\title{
Evaluation of Tectonic Activities Using LiDAR Topographic Data: The Nankan Lineament in Northern Taiwan
}

\author{
Kuo-Jen Chang ${ }^{1, *}$, Yu-Chang Chan ${ }^{2}$, Rou-Fei Chen ${ }^{2,3}$, and Yu-Chung Hsieh ${ }^{4}$ \\ ${ }^{1}$ Department of Civil Engineering, National Taipei University of Technology, Taipei, Taiwan, ROC \\ ${ }^{2}$ Institute of Earth Sciences, Academia Sinica, Taipei, Taiwan, ROC \\ ${ }^{3}$ Department of Geology, Chinese Culture University, Taipei, Taiwan, ROC \\ ${ }^{4}$ Central Geological Survey, MOEA, Taipei, Taiwan, ROC
}

Received 16 July 2008, accepted 17 November 2009

\begin{abstract}
The Nankan lineament and the Shanchiao normal fault are two major "structures" at the western and eastern boundaries of the Linkou Tableland. In contrast to the Shanchiao fault, the tectonic causes of the Nankan lineament have been studied and yet the results are rather inconsistent and controversial. The morphologic evolution is often the result of tectonic processes which can be regarded as the key information for revealing tectonic activity. This study takes advantage of high-resolution LiDAR images to re-examine the causes and tectonic activities of the Nankan lineament based on its morphological features. High-resolution morphological images enable detailed analyses of the major morphologic features of Nankan lineament and adjacent areas. The studied morphological features were analyzed based with several morphotectonic methodologies, including the curve fitting of river profiles, topographic anomaly analysis and a variation of contour density. The results reveal that Nankan lineament does not possess significant geomorphologic signs of recent tectonic activities. Thus, with the new morphological information based on LiDAR images, it seems reasonable to assert that the Nankan lineament has not been tectonically active recently or if so the lineament has healed and is now concealed by the subsequent surface processes.
\end{abstract}

Key words: Nankan lineament, Morphotectonics, River scarp, LiDAR, Linkou tableland

Citation: Chang, K. J., Y. C. Chan, R. F. Chen, and Y. C. Hsieh, 2010: Evaluation of tectonic activities using LiDAR topographic data: The Nankan lineament in northern Taiwan. Terr. Atmos. Ocean. Sci., 21, 463-476, doi: 10.3319/TAO.2009.11.17.01(TH)

\section{INTRODUCTION}

Taiwan is situated on an active orogenic belt and therefore possesses high seismicity and frequent geological hazards. More than 9 severe inland earthquakes have been recorded since last century with magnitude higher than 7 (Cheng and Yeh 2004). Unfortunately, most of the seismogenic faults pass across dense population areas and cause severe damage. The active faults identified are distributed throughout the island (Chang et al. 1998; Lin et al. 2000). Although fault movements have been observed, the possibility of co-seismic movements of many other faults is unknown and may pose severe threats to human life and property.

In order to identify the menace brought by fault movements, characterization of the activity of a fault is consid-

\footnotetext{
* Corresponding author

E-mail: epidote@ntut.edu.tw
}

ered to be an essential task especially for the faults without any historic earthquake record. Despite the significantly improved technology associated with morphological study, including geodesy, remote-sensing, geospatial information system and geochronology etc., the ability and availability of tools for exploring the activity of an existing fault are still limited. If paleoseismology and morphotectonics studies can be conjunctly adopted, more information can be revealed so as to facilitate the identification of the fault activities.

The study of paleoseismology allows characterizing the timing and the recurrence of a specific fault. In contrast to paleoseismology, morphotectonic study allows locating faults and the affected zones over a large area and provides a general idea regarding the relative activity. Moreover, the results of morphotectonic analysis may furnish useful information for future research. Therefore, morphological analysis is the fundamental study which should be conducted prior to other subsequent analyses. 
Prior to fault movement, supposing that the geomorphologic feature should be continuous and can be tracked based on the homogeneous geologic and natural conditions, and the undisturbed feature itself, in general. If the landform subjects a tectonic activity, the original geomorphologic feature could easily been perturb. Any evidence departs from their unperturbed shape may serve as hints indicating the occurrence of the fault movement. Using a digital terrain model (DTM), a geometric feature may be qualitatively and quantitatively defined, and then, geometric measurement and corresponding interpretation can be performed. In order to define tectonics activity, it is necessary to define both the timing and amount of deformation. However, owing to limited datable materials, the timing of deformation is not discussed in this study and is beyond the scope of this study.

A modern landform typically contains information used to decipher the possibility of tectonic activity. Unfortunately, information may often be concealed by subsequent surface processes. Morphotectonic analysis requires detailed surface features which are in turn dependent on morphological data with fine precision. For most conventional remote sensing applications, aerial photographs and satellite imagery are the usual tools. However, since the morphological features are often perturbed by subsequent surface processes, the limited precision of these two methods will not be adequate in performing a detailed analysis. In order to differentiate mircomorphologic character, airborne Light Detection and Ranging (LiDAR) technique is deployed to produce high-resolution and high-precision data in this study.

Airborne laser altimetry, e.g., LiDAR, is a sophisticated instrument recently developed. It possesses highresolution, high-precision and object-penetrating/filtering capacities, and proved to be an excellent tool in extracting surface features. Consequently, quantitative studies were undertaken to characterize the active fault and its structural implication (Chan et al. 2007) to map landforms for structural interpretations (Ganas et al. 2005) and for surface processes in mountainous terrain (Bishop et al. 2003; Cavalli et al. 2008; Norton et al. 2008). LiDAR images have also been applied to geotechnical engineering studies, including landslide delineation and risk assessment (Gritzner et al. 2001), landslide morphology, activity analysis, and the cutand-fill volume estimation (Chen et al. 2005, 2006; Chang et al. 2005, 2006; Glenn et al. 2006). Recently, the study of mapping of urban buildings, drainage networks and forests identification and management has also been achieved by means of LiDAR data (James et al. 2007; Miliaresis and Kokkas 2007; Zhang 2008).

The Linkou Tableland, adjacent to metropolitan Taipei is densely populated and industrialized (Fig. 1). The existence of active faults and its activities along the boundary of Linkou Tableland have become a major concern. The purpose of this paper is to explore the possibility of neotectonic activities in this area. This tableland is bounded by Shanchiao fault and Nankan lineament. The activity of the Shanchiao fault has been discussed and concluded as an active normal fault, based on the historical record, seismic data, borehole and geophysical investigations. However, the activity of the Nankan lineament is still an open question and requires more study. This research attempts to characterize the tectonics activity based on the morphotectonic analysis. In addition, the inter-relationship of tectonic processes, fluvial processes and the corresponding morphologic evolution near the study area are accordingly discussed.

\section{METHODOLOGY}

\subsection{The Use of LiDAR Technique}

Landscape elements typically conceal the information used to decipher the tectonic activity. This information may be discovered through various geomorphic analyses. In performing geomorphology analysis, DTM is essential and is generally available either through satellite images or aerial photographs with moderate precision and typically used for map generation with a scale ranging from 1/100000 to $1 / 5000$. This precision does not meet the requirements for detailed morphology analysis. DTM obtained through LiDAR images has such precision, generally ranging from $1 / 2500$ to $1 / 500$, and is superior in terms of accuracy and resolution to those images obtained from satellites or aerial photos. In this research LiDAR images are the fundamental sources for generating better and more precise DTM.

To obtain LiDAR images, laser altimetry scanner is mounted in the bottom of the fuselage of an aircraft or helicopter. The entire unit is composed of an integrated laser altimetry scanner, a Global Positioning System (GPS), and an inertial measurement unit (IMU). The position of the platform is determined by the GPS and the IMU. During recording operations, a steady laser beam is emitted toward ground targets; the reflected signals are received and recorded with reference to various relevant data such as traveltime and the angles of the laser beam. The integrated GPS and IMU units are responsible for calculating the relevant ground surface position and elevation by correlating the aircraft position and the measured distance corresponding to the pulse return rate.

The advantage of LiDAR is the capability to record the captured reflection intensity in addition to the position coordinates from the same pulse. The emitted light pulse is capable of penetrating some of the barrier above the ground surface while recording the corresponding returns which have been reflected from different media. The multiple laser returns provide a means of distinguishing the types of objects, such as canopy, roof top and bare ground, based on the intensity and time of arrival.

In this research, the Optech ALTM3070 apparatus, which records elevation measurements at a rate up to 71000 
pulses per second with sub-metric vertical precision, was deployed. A sorted dense point clouds acquiring from the return pulse represent LiDAR data after removing light objects including cloud and bird etc. The so-called digital surface model (DSM) is extracted from the sorted point clouds, based on the first return of the laser scanning, which has been reflected from the top of vegetation or buildings. In turn, the last returns are then occurred after the vegetation was been penetrated and then resumed the appearance of the bare ground surface by the reflection of the laser pulse. Meanwhile, a building can also be eliminated by processing nearby reflecting signals. As a result, the ground surface without vegetation and buildings can be obtained, which is referred as a digital elevation model (DEM).

In this study, DSM and DEM are regenerated in a grid size of 2-m from the original classified point cloud. The average density of point clouds for DSM and DEM are 3.63 and 0.75 point $\mathrm{m}^{-2}$, respectively. Comparing GPS measured data from different areas, it is found that the error may vary in accordance with differences in terrains; the average mean errors, RMS and STD are 0.097, 0.126, and $0.081 \mathrm{~m}$, respectively.

\subsection{Morphotectonics Analysis}

In order to qualitatively and quantitatively extract the deformation that has occurred due to tectonic processes, it is necessary to have an identifiable feature that has been moved. Otherwise, the magnitude of deformation may also be suggested if an initial undeformed geometry could be reasonably proposed against the present geomorphologic appearance. The more we know about the geometry, the better we can estimate the deformation.

Landscapes subjected simply to geomorphic and surficial processes tend to degrade and flatten, in general. Modification of an original undisturbed surface by subsequent (a)

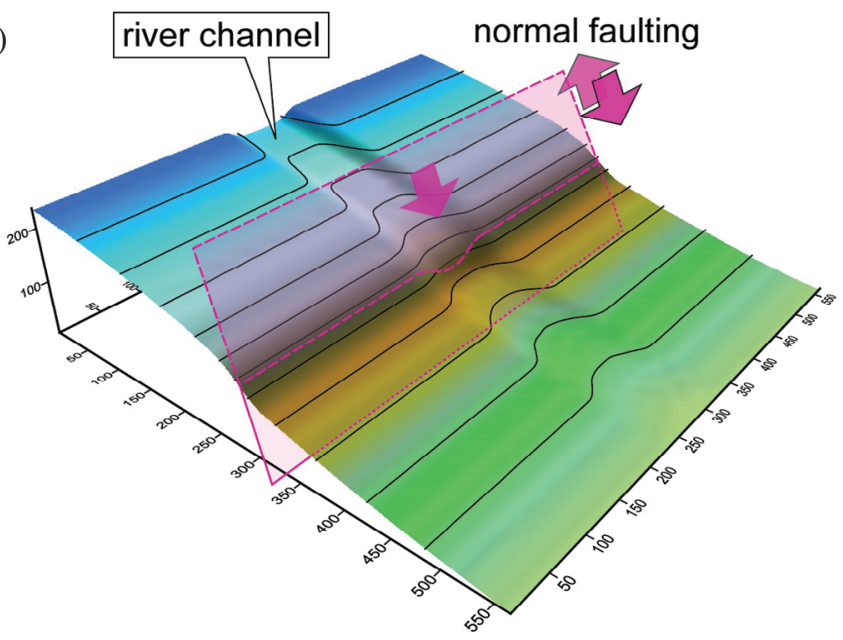

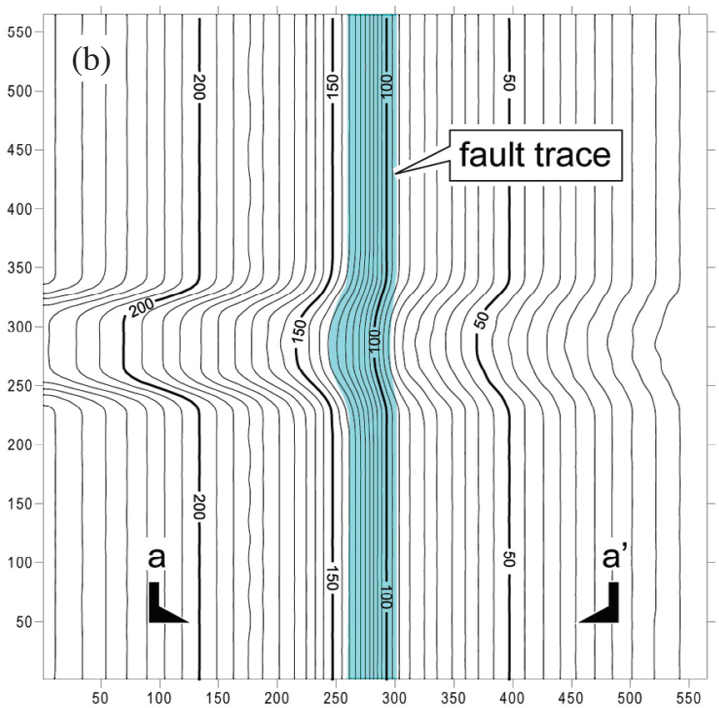

(d)
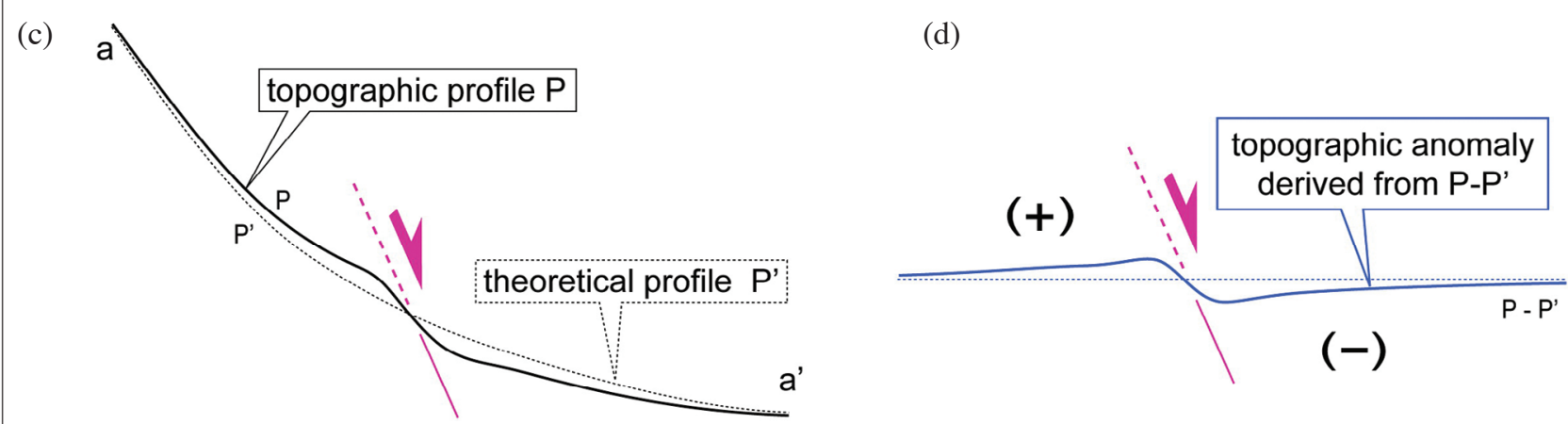

Fig. 1. Schematic block diagram and its corresponding profile showing the morphologic anomaly revealed by the variation of contour spacing in the map (b) and theoretical curve-fitted profile [(c) and (d)]. Tectonic activity may truncate or bend the topographic morphology and fitted by mathematical regression. 3-D block diagram of a normal faulted area (a) and its corresponding contour map (b) depict the concept of the distribution of contour lines, schematically. The inconsistency between the real profile $(\mathrm{P})$ and its theoretical fitted profile ( $\left.\mathrm{P}^{\prime}\right)$ could be enhanced by the difference in elevation, e.g., P - P' in mathematic subtraction operation. (d) demonstrates two different domains of topographic anomaly situating on the hanging wall and foot wall, separately. The location of the profile $\mathrm{P}$, shown by $\mathrm{a}-\mathrm{a}$, is situated on (b). 
surface processes, e.g., erosion and deposition, may make it more difficult to define the original geometry of a presently offset geomorphic surface. However, the modification of the surface may also establish a dynamically steady state landscape, which allows degradation and smoothing a disrupted surface. The degraded landform provides a smooth surface which enhances the signals of subsequent processes of recently activated tectonics.

In order to use a reference frame to the measured deformation, the initial, pre-deformation geometry of a geomorphic feature must be defined. In tectonic geomorphology, several identifiable features of surfaces may provide a reference frame against which deformation may be performed. However, because of surface processes, a presently exposed surface reveals only fragments of formerly continuous surfaces or features. The reliable reconstruction of the undeformed geometry is considered an essential process, and serves as the deformation calibration. Therefore, several features and methodology have been used in this study.

As a result of recently activated structures, surface deformations will show geomorphic characteristics such as linement, tectonic scarps, lateral offset of landforms, tectonic depressions, tectonic bulges, and surface inflexion, etc. These features indicate that the linear or planar morphologic geometry has been truncated by faulting or folding and some of them have been well discussed (Wesson et al. 1975; TRGAFJ 1980, 1992). Moreover, some associated surface deformations that may also occur around the main fault trace, e.g., crestal graben, etc., have been addressed (Philip and Meghraoui 1983; Philip et al. 1992).

During long intervals of tectonics quiescence, the topography of a landform may achieve a planar and low-relief landscape, e.g., Peneplane, by the subsequent surficial erosion and deposition process (Easterbrook 1999; Burbank and Anderson 2001). Since, the low-relief flat surface has been offset by later tectonic activity; the one continued plane may separate into several discontinued surfaces. The junction area may give rise to some geomorphic anomalies. These geomorphologic anomalies then may be identified from map, remote-sensing image interpretation or from field investigation. However, several surface processes may also contribute to generation and modification of the scarp, and identifiability of the scarps depends on data resolution as well. Regardless of the ocular identification around land scarp, topographic change will modify the spacing of contour lines. The low resolution DEM and images provide a general view and conceal the detail micromorphologic analysis. Based on the high-resolution DEM, the density and spacing of contour lines around somewhere of the elevation have been changed, which will act as an indicator for morphology analysis.

A smooth surface will develop within an area where no perturbation is performed. Tectonic activities affect surficial topography and change the gradient of slope; therefore, the spacing of contour lines of a map may change its density (Figs. 1a and b). Thus, the distribution and variation of contour density could be an indicator in a 2D surficial signal for morphotectonic analysis. Figure 1 depicts the ideas schematically in a 3-D block diagram and the corresponding contour map of a planar slope affected by normal faulting. In spite of some surficial degradation or slope retreat by the subsequent surface processes, the distribution of contour lines has been compressed around the scarp (hatched area in Fig. 1b). Note that, in the slope area, the density of a contour line may denser in a slope area than a river channel, since the river process modifies and conceals topographic signals.

On the other hand, any profile of a surface may exhibit a smooth curve (profile P' in Fig. 1c) and can be mathematically fitted into a model (profile P' in Fig. 1c). The difference between the real profile and fitted model may result from different lithology, erosion-deposition phenomena or active deformations. The fitting result could be improved by the process of fitting by small interval of the profile. An altimetric anomaly could be enhanced by the difference between the best fitted curve and the real profile, i.e., $\mathrm{P}$ minus P'. After the enhancing process, two domains may form by the depleted and the accumulated area at the two sides of the normalized profile and may indicate the presence of some subsequent activities (e.g., normal faulting in Fig. 2). By comparing the current profile and the best fitted curve, the quantity of surface processes or tectonic activities can be accordingly estimated (Angelier and Chen 2002; Delcaillau 2004). The difference between the real profile and best fitted curve may be healed by surface processes and estimated according to the diffusion model of a hillslope (Anderson 1994; Tucker and Slingerland 1994; Martin 2004; Nash and Beaujon 2006; Pelletier et al. 2006; Pelletier 2007). It is worth noting that the landform degradation by the subsequent surface process may eliminate or conceal activated tectonic signals. Thus, no significant morphological anomaly does not preclude the possibility that no tectonic activity had ever occurred.

\section{GEOLOGICAL SETTING}

Taiwan is an active orogenic belt formed by an oblique convergent between the Luzon arc of the Philippine Sea Plate and the Chinese continental margin on the edge of the Eurasian Plate (Ho 1986; Malavieille et al. 2002). Regardless of the ongoing collision in central and southern Taiwan, a post-collisional extension regime has developed since the Plio-Pleistocene in the northern part of this orogeny (Teng 1996) and led to the generation of volcanic activity onshore and offshore northern Taiwan (Wang et al. 1999).

The Linkou Tableland is bordered by the Taipei Basin to the east, the Western Foothills to the south, the Taoyuan Tableland to the west and the Taiwan Strait to the north. 
The east margin is defined by the Shanchiao normal fault, separated the Taipei Basin and the Western Foothills. The west margin is limited to the Taoyuan Tableland (Taoyuan terrace) by the Nankan lineament, as shown in Fig. 2.

The sub-triangular Linkou Tableland is a fairly flat and dissected terrace about $220-250 \mathrm{~m}$ in height (Fig. 1). It is capped with lateritic soil near the top surface and underlain by flat-lying Pliocene-Pleistocene conglomerates, sandstones, and mudstones. The Pliocene-Pleistocene strata are considered parts of a sedimentary fan-delta derived from the Western Foothills and Hsuehshan Range corresponding to the erosion of the mountain range (Teng et al. 2001). The sedimentary rocks are considered to have been transported by the ancient Hsintien (Ichikawa 1929; Wang Lee 1969) and Keelung Rivers (Hanai 1930; Tien et al. 1995). The sedimentary strata can be divided into two coeval rock units: the gravel-dominated Linkou Formation in the east and the sand-and-mud-rich Tananwan Formation in the west (Teng et al. 2001). Paleo-current analysis, by means of the analysis of the boulder size distribution and the direction of imbri- cated cobbles, indicates that the fanhead is situated near the Taishan area on eastern boundary of the Linkou Tableland (Chen 1989). North of the Linkou Tableland, a part of the flat Linkou-Tananwan strata was tilted by igneous intrusions in the Kuanyinshan area. These intruded and covered andesitic to basaltic rocks are known as Kuanyinshan volcanic rocks and have been estimated as being 0.2 to $0.6 \mathrm{Ma}$ (Juang and Chen 1989; Tien et al. 1995). Recent studies suggest the age of the top formation of Linkou Tableland should be as young as $400 \mathrm{Ky}$ (Teng and Song 2007) according to the stratigraphic correlations of the volcanic debris and the sedimentary deposits.

The late Paleogene to Neogene sedimentary rocks, shown in Fig. 2, defining by a series of imbricated west vergent and trending NE-SW folds and faults, is recognized as a region of foreland fold-and-thrust regime (Suppe 1981; Ho 1986). The so-called Hsinchuang Fault is considered a collisional syn-orogenic front thrust of the mountain range and runs approximately parallel to the east and south boundary of Linkou Tableland. This mountainous fold-and-thrust

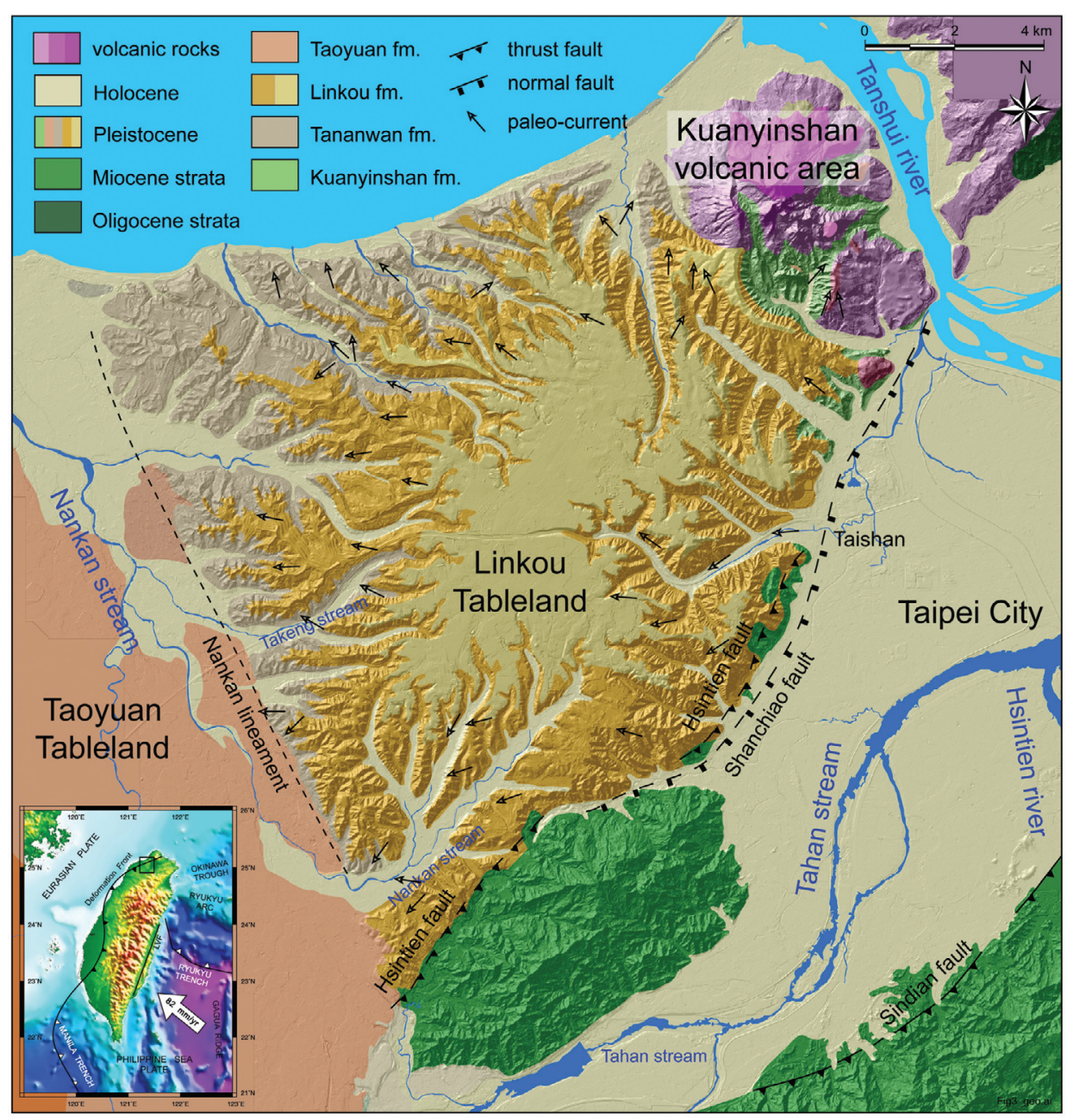

Fig. 2. Geodynamic and regional geological map around the studied area. The Linkou Tableland is confined by the Shanchiao normal fault in the east and Nankan lineament in the west. A flat lateritic soil capped on the top of Linkou top surface. 
belt provides the source and then is deposited in the foreland belt, e.g., Linkou Tableland, during the ongoing orogeny process in Taiwan. The post-orogenic relaxation reverted the tectonics to the extensional regime, causing the formation of the Taipei Basin.

The Taipei Basin forms an asymmetric wedge shaped half-graben and is filled up with Quaternary siliciclastic sediments. The maximum depth of the depocenter is about $700 \mathrm{~m}$ near the east margin (Wang and Sun 1999), which is defined by the Shanchiao normal fault (Teng et al. 2001; Chen et al. 2007; Huang et al. 2007). This fault performs an outstanding linear scarp, which separates the Linkou Tableland and the Taipei Basin (Chen 1953; Lin 1957). The formation and subsidence of the Taipei Basin along the Shanchiao fault is interpreted as a result of tectonic inversion of the Hsinchuang thrust fault (Chiu 1968; Hsieh et al. 1992). The accumulation of fluvial and lacustrine sediments around and beneath the Taipei Basin is estimated to have started at about 0.4 Ma (Wei et al. 1998; Teng et al. 2001), and coincides with the age at the top of Linkou Tableland.

The Taoyuan Tableland, located to the west of the Linkou Tableland, consists of Pleistocene conglomerates and sandstones overlain by a lateritic soil (Fig. 2). The Taoyuan Tableland could be divided into six different terraces, the Hukou terrace, the Fukang terrace, the Yangmei terrace, the Talun terrace, the Chungli terrace, and the Taoyuan terrace, from the highest to lowest respectively (Lin 1957; Ku 1963; Yang 1986; Teng 2003; Lin et al. 2007). The youngest terrace has been suggested to be the Taoyuan terrace according to its lowest elevation (Huang 1995; Wang 2003) and pedogenic correction (Lin et al. 2005 and 2007). The Taoyuan terrace consists of a few to tens of meters deep orange-to-red lateritic soil overlaying the partially lateritic conglomerate.

The property and behavior of the Shanchiao fault have been discussed for a long time because of its distinct linear scarp, historical seismicity record and affiliated co-seismic subsidence (Chen 1953; Lin 1957). The elevation difference between the Linkou Tableland and the Taipei Basin is as much as $200 \mathrm{~m}$ in height. Recent studies reveal its high tectonic activities, including geomorphic and geologic analysis by borehole investigation and record (Chen et al. 2007; Huang et al. 2007; Song et al. 2007), by the geodetic study (Yu et al. 1999) and by the micromorpholoic study (Chen et al. 2006). Compared with the Shaochiao normal fault, however, the geometric property and tectonic activity of the Nankan lineament have not been well resolved.

The linear scarp of the Nankan lineament is about $100 \mathrm{~m}$ height. Hanai (1930) proposed that the scarp was either a fault scarp by quaternary normal faulting or a river scarp formed by river incision. The idea of normal faulting has been proposed by Lin (1957) and by Ku (1963) based on geomorphologic characteristics. Yang (1986) suggests that there is an inconsistency of morphologic correlation based on the degree of top soil lateritization, and material proprieties in two sides of the scarp. Chen et al. (1994) documented two outcrops with some small shear zones, but the outcrops situated somewhat far away from the linear scarp, also, the direction of paleo extensional stress analysis in N105E which is about $30^{\circ}$ differ from the so-called Nankan lineament. Most of the geophysical investigations show no significant stratific separation (Hsiao 1967; Liang et al. 1985; Tsai 1986; Tsai 2007). This result is also confirmed by borehole investigations (Heshie Engineering 1999). However, some the exceptions are also reported (Yeh et al. 1985; Chen et al. 1988; Sun 1995; Hsieh et al. 1997). It is worth noting that Sun (1995) and Hsieh et al. (1997) propose a thrust model. Despite many documents reported, the un-converged conclusion demonstrates that the property and the activity of the Nankan lineament is still a highly debated topic.

\section{RESULTS AND DISCUSSION}

\subsection{General Morphology in Linkou Tableland}

The average elevation of the Linkou Tableland ranges from 220 to $250 \mathrm{~m}$ above sea level. The top surface of the tableland shows a dramatic flat surface (Fig. 3). The elevation of the top surface is about $240-250 \mathrm{~m}$ and is capped with lateritic soil. The mean elevation of the top surface shows the highest center situated on the south-eastern changing gradually to NNE (Fig. 3). Within the tableland, streams develop in a sub-radial drainage pattern. Much of the streams develop dendritic drainage patterns by a random headward erosion of the insequent gully. Between the low and the middle stream, the stream channel forms a box shape, showing wide flat bottom with steep lateral bank. On the up stream, the V-shape concave upward sections of stream channels manifest its strong headward erosion.

The characteristics of the river longitudinal profile are affected by eustatic or tectonic activities. Table 1 demonstrates some of the stream information of the river profiles situated around the Linkou Tableland. The corresponding locations of the streams listed in Table 1 are indicated in Fig. 3. In the east boundary of the Linkou Tableland showed in Fig. 3, closed to the Shanchiao fault, streams develop in a shorter length, straight channel and high slope gradient of about $2.4-6.2 \%$. Near the western edge of the tableland, however, longer length and lower slope gradient ranging about $1.3-2.2 \%$, parts of meanders have also been developed. This phenomenon implies the gullies in the east may be more juvenile than those situated in the western boundary of the tableland.

\subsection{Surface Features on the Nankan Lineament}

The topographic evolution of mountain front depends strongly on the relative rates of faulting, erosion and deposition (Ellis et al. 1999). Rivers flowing across the fault 
from the uplift block will tend to dissect the mountain front, whereas activities faulting will tend to restore its linear character. The spacing of triangular facets along range fronts reflects the evolution of drainage basins on the uplifted block.
High-resolution topographic data have the potential to differentiate the micromorphological features of a landform. Recent tectonic activities affect a small but distinct morphologic anomaly. The identifiability of these micromorpholgic signals depend on the resolution and the quality of images

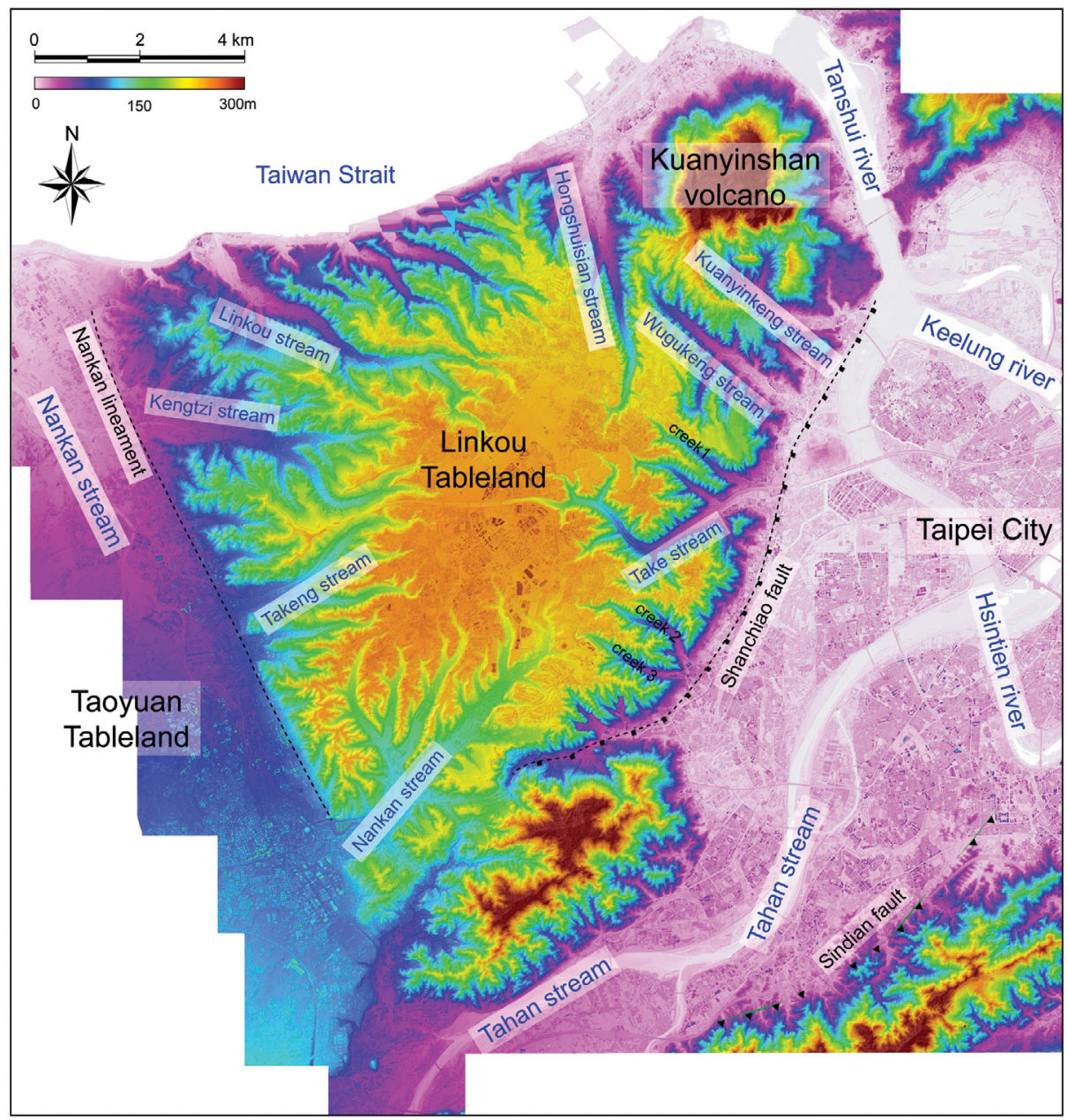

Fig. 3. Shaded geomorphologic map demonstrating the general landform of Linkou, Taoyuan Tableland and Taipei Basin. The sub-triangular Linkou Tableland showing its outstanding flat but dissected surface in 220 - $250 \mathrm{~m}$ height.

Table 1. Stream information of the river profiles situated around the Linkou Tableland.

\begin{tabular}{lcccc}
\hline River & Horton-Strahler order & Area $\left(\mathbf{k m}^{2}\right)$ & Length $(\mathbf{k m})$ & Slope $(\%)$ \\
\hline Kengtzi stream & 7 & 19.15 & 9.25 & 2.086 \\
Takeng stream & 7 & 9.20 & 7.32 & 2.287 \\
Nankan stream & 8 & 31.62 & 12.01 & 1.325 \\
Wugukeng stream & 7 & 10.93 & 6.32 & 2.476 \\
creek 1 & 5 & 2.57 & 4.30 & 4.953 \\
creek 2 & 5 & 3.54 & 4.15 & 5.244 \\
creek 3 & 5 & 2.42 & 3.32 & 6.212 \\
\hline
\end{tabular}


available. Data with insufficient or limited precision would not be adequate in performing the detailed analysis of surface perturbation. Figure 4 showing the pseudo distinct lineament along the study area is based on the IKONOS $1 \mathrm{~m}$ resolution and $40 \mathrm{~m}$ grid DEM. The landform and vegetation are different at two sides of the Nankan Lineament, as showed in Fig. 4.

In this study high-resolution LiDAR DEM and DSM have been deployed in order to extract detailed surface features. Figure 5 illustrates four morphologic profiles across the Nankan lineament. The choice of these four sections is based on its homogeneous morphologic and geologic characters. Among four sections, three of them are situated near the recent river flood plane with minor artificial modification possible, e.g., agriculture activities and human development. The other one is situated out of the talus cone deposits, the toe of the scarp, to the higher slope, also with minor slope modification possible. The artificial terrain modification could be recognized by comparing the DEM, DSM, high-resolution aerial photos and satellite images.

The topographic profiles have been fitted often by a mathematic expression, e.g., exponential law, in order to exaggerate and identify the morphotectonic anomalies. Figure $5 \mathrm{~b}$ shows the fitted results with the coefficient of determination, $\mathrm{R}^{2}$. The higher $\mathrm{R}^{2}$ values express higher coherence between the current and fitted profile, mathematically. The difference of elevation between the best-fit and the real DEM, shown in Fig. 5c, has been elaborated by simply subtracting mutually in order to extract the morphological anomaly. The arrows indicate the corresponding position in respect to the Nankan lineament. As above-mentioned, the curves demonstrating the difference between two profiles, e.g., Fig. 5c, may be performed if there is a depleted and accumulated region in respect to two sides of the tectonic activity. In Fig. 5c, however, no significant anomaly or two domains in two side of the profile has been identified. It may easily be explained by the shortage of recent tectonic activities across the profiles.

Furthermore, two different positive and negative anomaly domains may be performed in two sides of the fault scarp, after the normalizing the topographic profiles. The tectonic activity may truncate and affect the morphologic slope, resulting in a sinuous curve of the slope profile. Furthermore, twelve topographic profiles across the Nankan lineament have been analysis and are shown on Fig. 6. In order to prevent the disturbance the morphological interpretation, the profiles are been chosen where the minor artificial modifications possible. In this figure, however, no distinct sinuous curve was found.

On the other hand, the spacing variances of a contour map may be an indicator of tectonic activities in 2-D surface analysis. Figure 7 depicts the result derived from LiDAR DEM. Two target areas have been chosen for the possibility of a few artificial modifications, Fig. 7. These different terrains may reveal some information to verify if there is a morphologic anomaly. Two enlargements, shown on Fig. 7, illustrate the target terrains with contour maps situated on the morphologic scarp and river flood plane, respectively. Regardless of some zigzagging contour lines affected by terrain irregularities on the river flood plane, systematic changes and an equal spacing in the density of contour lines are depicted in these two areas, respectively. This phenom-

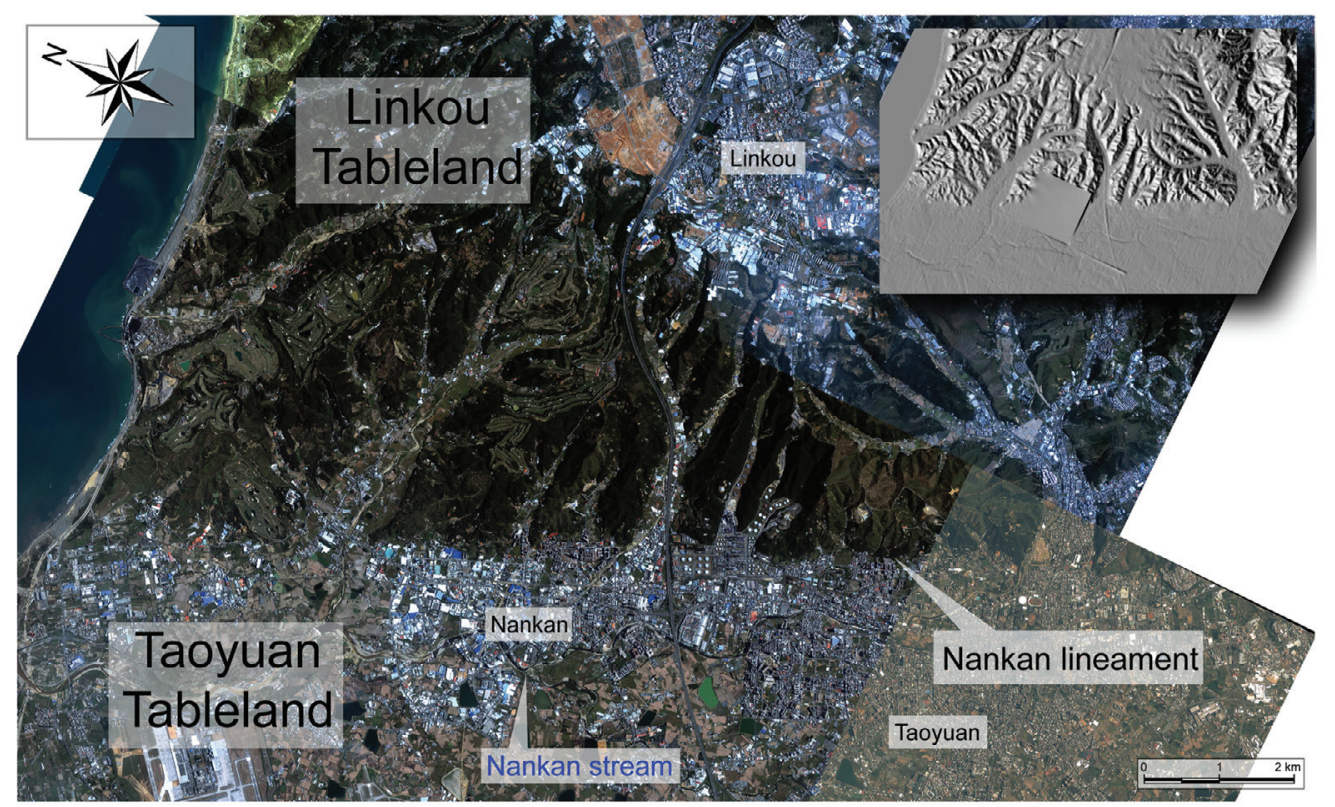

Fig. 4. IKONOS image and $40 \mathrm{~m}$ grid DEM showing two topographic domains by different landform and vegetations in the study area. The topographic boundary has been regarded as a lineament which separates two different levels of geologic terraces. 
enon implies there is no significant tectonic anomaly across this area.

The Nankan fault has been identified from its distinguishing lineament based on a low resolution topographic map. By means of LiDAR DEM data, hillshaded 3-D block diagram has been preformed in order to demonstrate and reexamine the linear trend of morphologic features (Fig. 8). Notwithstanding the linear scarp dissects the Linkou and Taoyuan Tableland, most part of the linear morphologic scarp does not perform, however, with some typical triangular facets or the wine-glass valleys. The triangular facets and wine-glass valleys depict some slope degradation or surface processes which have been preformed along the linear terrace riser. Only a small segment of scarp, situated between Nankan stream and Takeng stream, may suggest a continuous linear scarp. Despite linear scarp marked in this segment, the trend shows a slightly concave curved to Linkou Tableland (Fig. 8). The profiles of the facets perform also a continuous concave upward slope, which differ from typical planar facets affected by faulting (enlarge figure in Fig. 8). Between two facets, a small fan may exist if there is a gully developed within. On the other hand, a smooth increasing gradient and continuous slope is depicted within this segment, without showing a morphologic anomaly.

It is worth noting that, in the enlargement figure in Fig. 8, the Nankan River turns to NW after leaving out of

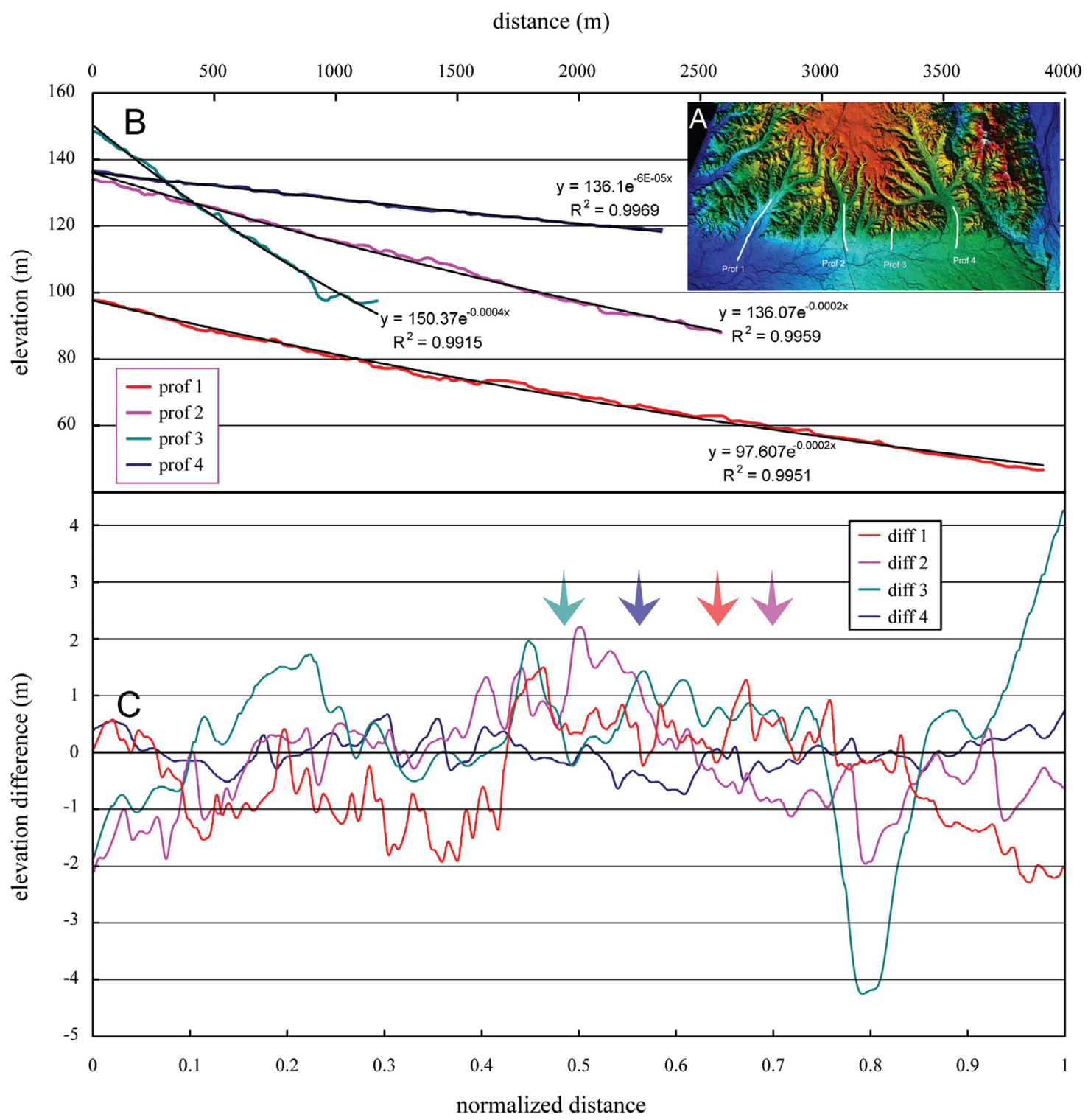

Fig. 5. Four topographic profiles across the Nankan lineament combined with curve-fitting results. (a) The indication of location for four sections. (b) The formulation of regression result with coefficient of determination. (c) The difference of elevation calculated from the profiles vs. curvefitting results. The arrows indicated the corresponding position with respect to the Nankan lineament. On two sides of the linement, no distinct morphologic anomaly has been identified in order to separate two different domains. 


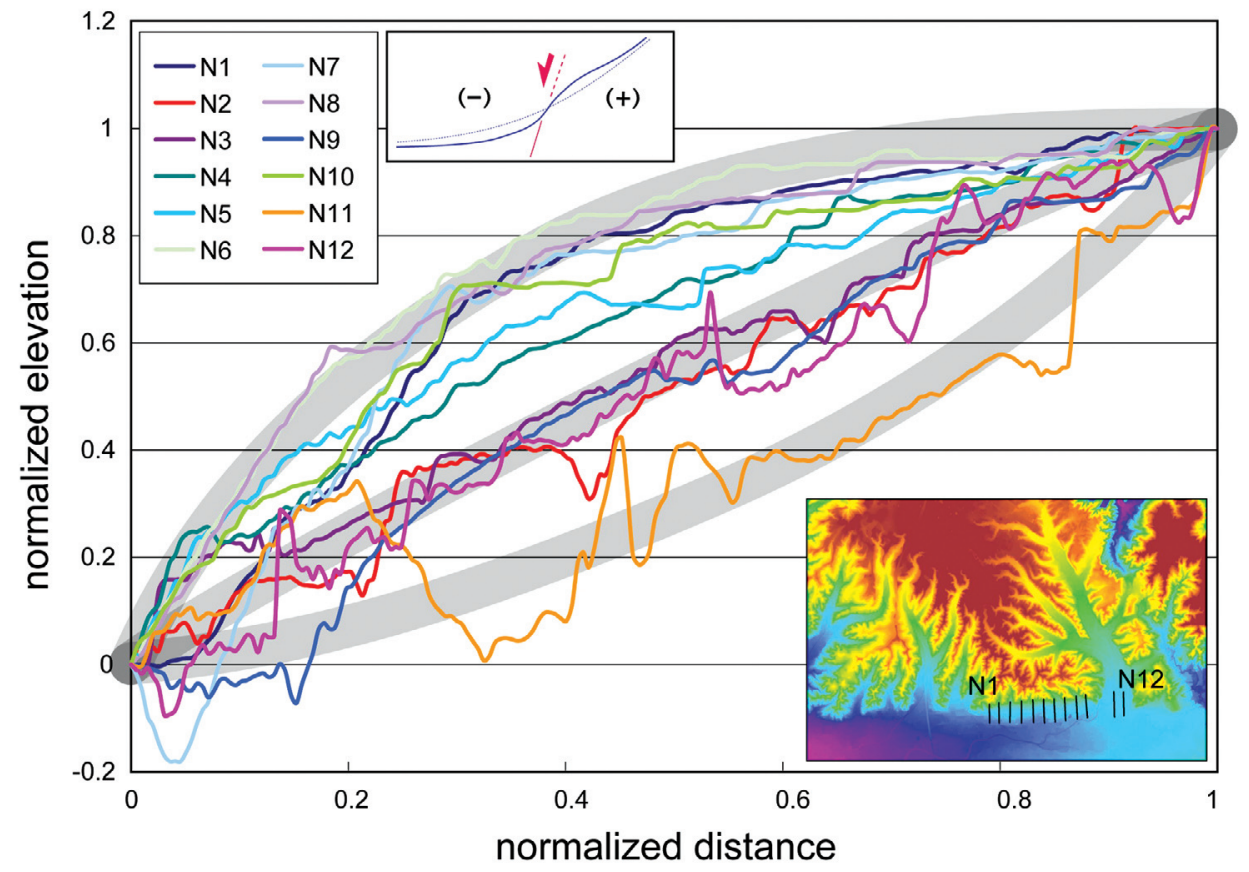

Fig. 6. Twelve topographic profiles across the Nankan lineament situated where minor artificial modification may be found around the study area. The schematic ideal model may be presented by the fitting of the mathematic model and demonstrating two positive and negative anomaly domains in two sides of the fault scarp. The topography may perform a sinuous curve and implying the tectonic activities. On this figure, however, no distinct sinuous curve has been performed.

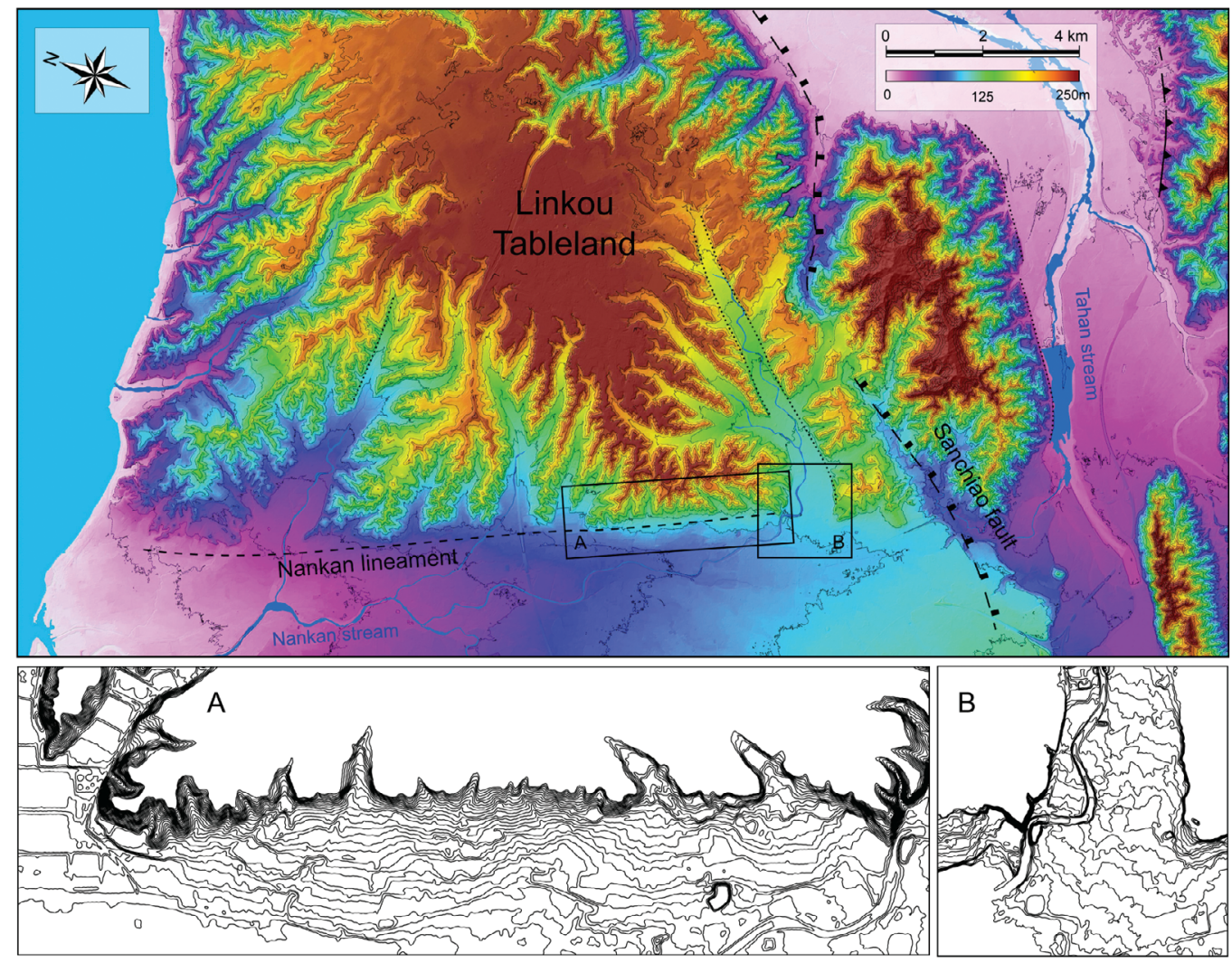

Fig. 7. Topographic map with contour lines around the Nankan lineament showing the spatial variation of contour lines. The tectonic implications have been mentioned in the text and as illustrated in Fig. 1. Two enlargements perform the spatial variation in detail. A: The contour lines depicted from 80 to $140 \mathrm{~m}$ with a 2 meter interval. B: The contour lines depicted from 95 to $115 \mathrm{~m}$ for every 1 meter interval. Two sub-figures demonstrating only a systematic variation of the contour density, and may suggest that there is no significant tectonic activity in these two areas. 


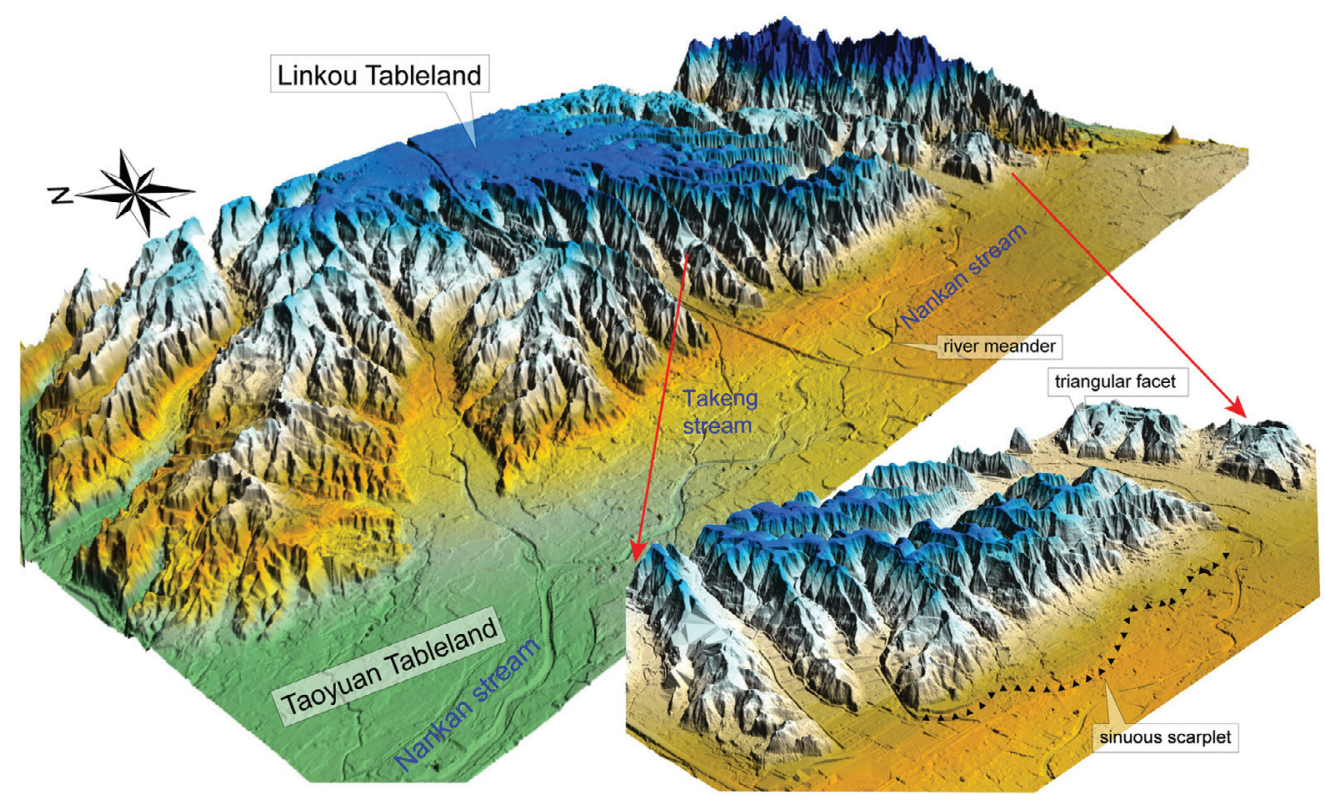

Fig. 8. Elevated hillshading map of the study area obtained from LiDAR DEM. The morphologic feature may be enclosed by a topographic lineament. Some of the triangular facets appeared on the blow-up. The river channel of Nankan stream develops a sinuous scarplet (indicating by small triangles) and meander on the Taoyuan Tableland.

Linkou Tableland. The river channel flows as a meander on the Taoyuan Tableland. Not far from the current channel, a sinuous scarplet demonstrates the existence of a paleo river bank, shown with a small triangle on blow-up of Fig. 8. The sinuous scarplet, however, is different from the position and the geometry of the current channel. These phenomena imply the effect of migration and incision of the current river channel.

Compared with the Nankan lineament, serials of triangular facets in the up-stream of Nankan drainage basin are dramatically demonstrated within the Linkou Tableland. Parts of the triangular facets show in the top-left corn on the enlargement of Fig. 8. On the other hand, these triangular facets are arranged in a straight line and demonstrate a perfect linear/planar morphological lineament. These straight lineaments are distributed at two sides of the main river channels and also in much of the tributary of Nankan River. However, these lineaments are not considered as an effect of tectonic faulting and also there is no discontinuity or fault that has been documented, thus far. The same morphologic feature existed in the eastern boundary where the Shanchiao normal faulting cutoff the scarp. The straight river scarp was also found two sides of the streams arranging in a perfect linear shape, perpendicular to sub-parallel to the Shanchiao normal fault (Fig. 3). It has been well known, however, that the trace of the Shanchiao normal fault is not in the same direction as compared to the river scarps.

In the south of the Taipei Basin, the Tahan stream, a tributary of the Hsintien river, flows north-east as showing in Figs. 2 and 3. A straight and distinct river scarp depicts its striking morphologic feature situated on the boundary of Miocene sedimentary rock and the Quaternary alluvial deposits. Following up the scarp to south-west, the scarp is continued and prolonged to the lower Quaternary alluvial scarp with slightly curvature, as has been illustrated in Fig. 7. This morphologic feature demonstrates that the formation of this lineament is a river scarp and may link with the eustatic changes and related fluvial processes.

After an examination of the above-mentioned phenomena, the morphologic features of the Nankan lineament are not so clear based on the LiDAR DEM and DSM. The micromorphology demonstrated by LiDAR DEM did not show any significant morphologic anomaly. Regardless of the Nankan lineament is a scarp by tectonic faulting, the micromorphologic features imply that there may be no recent tectonic activities or the rate of the surface processes is too fast to conserve most of the tectonic signals.

\section{CONCLUSION}

Remote-sensing technique advances allowed reliable morphologic survey to be achieved. The LiDAR data presented here do show the value of high-resolution digital surface image, DEM and DSM. Various approaches have been proposed and deployed in this study in order to assess the tectonic activity, including: 3-D ocular hillshading block diagram, river profile inflexion, knick-points, curvefitting, density variation of contour spacing, etc. However, the in two sides of the linement, no stronger evidence of the morphologic anomaly has been identified or performed by 
the LiDAR high resolution DTMs. Thus, the results of this study suggest that the Nankan lineament has not showed any significant tectonic activity recently or it has been healed and is concealed by surface processes. Clearly, the LiDAR technique plays an important tool for the tectonic activity analysis and natural hazard assessment, as well.

Acknowledgements We would like to thank Prof. FuShu Jeng for his help, which has improved the scientific soundness of this paper. We also thank Dr. Jian-Cheng Lee at the Institute of Earth Sciences, Academia Sinica for his encouragement and advice. We thank Prof. J. Y. Yen and an anonymous reviewer for a thorough review of the manuscript. This work was partly supported by the Central Geological Survey, MOEA and by the National Science Council of ROC (CGS96-5226902000-01-04 and NSC982628-M-001-015).

\section{REFERENCES}

Anderson, R. S., 1994: Evolution of the Santa Cruz Mountains, California, through tectonic growth and geomorphic decay. J. Geophys. Res., 99, 20161-20179, doi: 10.1029/94JB00713. [Link]

Angelier, J. and R. F. Chen, 2002: Empirical mathematical analysis of longitudinal river profiles reveals tectonic uplift and folding: A case in Taiwan. C. R. Geosci., 334, 1103-1111, doi: 10.1016/S1631-0713(02)018503. [Link]

Bishop, M. P., J. F. Shroder, Jr., and J. D. Colby, 2003: Remote sensing and geomorphometry for studying relief production in high mountains. Geomorphology, 55, 345-361, doi: 10.1016/S0169-555X(03)00149-1. [Link]

Burbank, D. W. and R. S. Anderson, 2001: Tectonic Geomorphology, Wiley-Blackwell, Massachusetts, USA, $274 \mathrm{pp}$.

Cavalli, M., P. Tarolli, L. Marchi, and G. D. Fontana, 2008: The effectiveness of airborne LiDAR data in the recognition of channel-bed morphology. CATENA, 73, 249260, doi: 10.1016/j.CATENA.2007.11.001. [Link]

Chan, Y. C., Y. G. Chen, T. Y. Shih, and C. Huang, 2007: Characterizing the Hsincheng active fault in northern Taiwan using airborne LiDAR data: Detailed geomorphic features and their structural implications. $J$. Asian Earth Sci., 31, 303-316, doi: 10.1016/j.jseaes.20 06.07.029. [Link]

Chang, H. C., C. W. Lin, M. M. Chen, and S. T. Lu, 1998: An Introduction to the Active Faults of Taiwan, Explanatory Text of the Active Fault Map of Taiwan. Spec. Publ. Cent. Geol. Surv., 10, 103 pp. (in Chinese)

Chang, K. J., A. Taboada, and Y. C. Chan, 2005: Geological and morphological study of the Jiufengershan landslide triggered by the Chi-Chi Taiwan earthquake. Geomor- phology, 71, 293-309, doi: 10.1016/j.geomorph.2005. 02.004. [Link]

Chang, K. J., A. Taboada, Y. C. Chan, and S. Dominguez, 2006: Post-seismic surface processes in the Jiufengershan landslide area, 1999 Chi-Chi earthquake epicentral zone, Taiwan. Eng. Geol., 86, 102-117, doi: 10.1016/j.enggeo.2006.02.014. [Link]

Chen, C. H., 1953: Taipei Basin: Its structure and formative factors. Acad. Rev., 2, 88-92. (in Chinese)

Chen, C. T., J. C. Lee, J. C. Hu, Y. C. Chan, and C. Y. Lu, 2006: The active Shanchiao Fault in the Metropolitan Taipei Area, Northern Taiwan: Geomorphic and geodetic analyses. AGU Fall Meeting Supplement, T33D0543, Abstract.

Chen, C. T., J. C. Hu, C. Y. Lu, J. C. Lee, and Y. C, Chan, 2007: Thirty-year land elevation change from subsidence to uplift following the termination of groundwater pumping and its geological implications in the Metropolitan Taipei Basin, Northern Taiwan. Eng. Geol., 95, 30-47 doi: 10.1016/j.enggeo.2007.09.001. [Link]

Chen, K. J., Y. H. Yeh, C. S. Tsai, and S. C. Yuan, 1988: Gravity and microearthquake studies in the NankanTauyuan area, northwestern Taiwan. Proc. Geol. Soc. China, 31, 125-139.

Chen, R. F., Y. C. Chan, J. Angelier, J. C. Hu, C. Huang, K. J. Chang, and T. Y. Shih, 2005: Large earthquaketriggered landslides and mountain belt erosion: The Tsaoling case, Taiwan. C. R. Geosci., 337, 1164-1172, doi: 10.1016/j.crte.2005.04.017. [Link]

Chen, R. F., K. J. Chang, J. Angelier, Y. C. Chan, B. Deffontaines, C. T. Lee, and M. L. Lin, 2006: Topographical changes revealed by high-resolution airborne LiDAR data: The 1999 Tsaoling landslide induced by the Chi-Chi earthquake. Eng. Geol., 88, 160-172, doi: 10.1016/j.enggeo.2006.09.008. [Link]

Chen, W. F., 1989: Stratigraphy and sedimentology analysis of Linkou Conglomerate. Master Thesis, National Taiwan University, Taipei, Taiwan, ROC. (in Chinese)

Chen, W. F., L. S. Teng, J. Angelier, J. C. Lee, and H. T. Chu, 1994: The Nankan faults outcrop. Ti-Chih, 14, 63-71. (in Chinese)

Cheng, S. N. and Y. T. Yeh, 2004: Centurial large earthquake in Taiwan. Sci. Dev., 373, 68-73. (in Chinese)

Chiu, H. T., 1968. The Hsinchuang Fault in the Taoyuan area, northern Taiwan. Proc. Geol. Soc. China, 11, 6073.

Delcaillau, B., 2004: Reliefs et tectonique récente, Vuibert, Paris, France. (in French)

Easterbrook, D. J, 1999: Surface Processes and Landforms, Prentice Hall, New Jersey, USA.

Ellis, M. A., A. L. Densmore, and R. S. Anderson, 1999: Development of mountainous topography in the Basin Ranges, USA. Basin Res., 11, 21-41, doi: 10.1046/ j.1365-2117.1999.00087.x. [Link] 
Ganas, A., S. Pavlides, and V. Karastathis, 2005: DEMbased morphometry of range-front escarpments in Attica, central Greece, and its relation to fault slip rates. Geomorphology, 65, 301-319, doi: 10.1016/j.geomor ph.2004.09.006. [Link]

Glenn, N. F., D. R. Streutker, D. J. Chadwick, G. D. Thackray, and S. J. Dorsch, 2006: Analysis of LiDARderived topographic information for characterizing and differentiating landslide morphology and activity. Geomorphology, 73, 131-148, doi: 10.1016/j.geomorph.2005.07.006. [Link]

Gritzner, M. L., W. A. Marcus, R. Aspinall, and S. G. Custer, 2001: Assessing landslide potential using GIS, soil wetness modeling and topographic attributes, Payette River, Idaho. Geomorphology, 37, 149-165, doi: 10.1016/S0169-555X(00)00068-4. [Link]

Hanai, S., 1930: Active faults in the Toen Hill, Formosa. Geogaph. Rev. Jpn., 6, 778-789. (in Japanese)

Heshie Engineering, 1999: Geotechnical Report of Nankan Fault Investigation, Heshie Engineering Consultants Ltd., Taipei, Taiwan, ROC.

Ho, C. S., 1986: A synthesis of the geologic evolution of Taiwan. Tectonophysics, 125, 1-16, doi: 10.1016/004 0-1951(86)90004-1. [Link]

Hsiao, P. T., 1967: Seismic study of the Taoyuan tableland, Taiwan. Petrol. Geol. Taiwan, 5, 63-79.

Hsieh, C. H., Y. F. Chang, and R. H. Sun, 1992: Seismic investigate Hsin-Chuan fault on the west of Taipei Basin. Ti-Chih, 12, 13-26. (in Chinese)

Hsieh, C. H., M. K. Sun, S. H. Hsieh, and C. W. Huang, 1997: Seismic mapping for Nankan fault in the Taoyuan area. Sino-Geotechnics, 64, 93-104. (in Chinese)

Huang, S. Y., C. M. Rubin, Y. G. Chen, and H. C. Liu, 2007: Prehistoric earthquakes along the Shanchiao fault, Taipei Basin, northern Taiwan. J. Asian Earth Sci., 31, 265-276, doi: 10.1016/j.jseaes.2006.07.025. [Link]

Ichikawa, Y., 1929: The gravel deposit of the Taoyen Tableland in Taiwan (Formosa). J. Geogr., 41, 396-403.

James, L. A., D. G. Watson, and W. F. Hansen, 2007: Using LiDAR data to map gullies and headwater streams under forest canopy: South Carolina, USA. CATENA, 71, 132-144, doi: 10.1016/j.CATENA.2006.10.010. [Link]

Juang, W. S. and J. C. Chen, 1989: Geochronology and geochemistry of volcanic rocks in northern Taiwan. Bull. Cent. Geol. Surv., 5, 31-66. (in Chinese)

$\mathrm{Ku}, \mathrm{C} . \mathrm{C}$., 1963: Photogeologic study of terraces in northwestern Taiwan. Proc. Geol. Soc. China, 6, 51-60.

Liang, C. H., L. M. Kuo, B. D. Lee, C. C. Chang, and T. M. Chu, 1985: Research on active fault in Taoyuan Hsinchu area: Resistivity method exploration. Technological report of Hazard prevention, National Science Council, Taipei, Taiwan, ROC. (in Chinese)

Lin, C. C., 1957: Geomorphology of Taiwan. Taiwan Provincial Documentary Committee, Taipei, Taiwan,
ROC. (in Chinese)

Lin, C. W., H. C. Chang, S. T. Lu, T. S. Shih, and W. J. Huang, 2000: An Introduction to the Active Faults of Taiwan, Explanatory Text of the Active Fault Map of Taiwan, $2^{\text {nd }}$ Ed., Special Publication of Central Geological Survey, 13, Central Geological Survey, Taipei, Taiwan, ROC. (in Chinese)

Lin, Y. S., Y. G. Chen, Z. S. Chen, and M. L. Heieh, 2005: Soil morphological variations on the Taoyuan Terrace, Northwestern Taiwan: Roles of topography and groundwater. Geomorphology, 69, 138-151, doi: 10.1 016/j.geomorph.2004.12.006. [Link]

Lin, Y. S., Y. W. Lin, Y. Wang, Y. G. Chen, M. L. Hsu, S. H. Chiang, and Z. S. Chen, 2007: Relationships between topography and spatial variations in groundwater and soil morphology within the Taoyuan-Hukou Tableland, Northwestern Taiwan. Geomorphology, 90, 36-54, doi: 10.1016/j.geomorph.2007.01.013. [Link]

Malavieille, J., S. E. Lallemand, S. Dominguez, A. Deschamps, C. Y. Lu, C. S. Liu, P. Schnürle, and ACT Scientific Crew, 2002: Arc-continent collision in Taiwan: New marine observations and tectonic evolution. In: Byrne, T. B. and C. S. Liu, (Eds.), Geology and Geophysics of an Arc-Continent Collision, Taiwan, Republic of China, Boulder, Colorado, Geological Society of America Special Paper, 358, 187-211.

Martin, Y., 2000: Modelling hillslope evolution: Linear and nonlinear transport relations. Geomorphology, 34, 121, doi: 10.1016/S0169-555X(99)00127-0. [Link]

Miliaresis, G. and N. Kokkas, 2007: Segmentation and object-based classification for the extraction of the building class from LIDAR DEMs. Comput. Geosci., 33, 1076-1087, doi: 10.1016/j.cageo.2006.11.012. [Link]

Nash, D. B. and J. S. Beaujon, 2006: Modeling degradation of terrace scarps in Grand Teton National Park, USA. Geomorphology, 75, 400-407, doi: 10.1016/j. geomorph.2005.07.027. [Link]

Norton, K. P., F. von Blanckenburg, F. Schlunegger, M. Schwab, and P. W. Kubik, 2008: Cosmogenic nuclidebased investigation of spatial erosion and hillslope channel coupling in the transient foreland of the Swiss Alps. Geomorphology, 95, 474-486, doi: 10.1016/j. geomorph.2007.07.013. [Link]

Pelletier, J. D., 2007: Fractal behavior in space and time in a simplified model of fluvial landform evolution. Geomorphology, 91, 291-301, doi: 10.1016/j.geomor ph.2007.04.015. [Link]

Pelletier, J. D., S. B. DeLong, A. H. Al-Suwaidi, M. Cline, Y. Lewis, J. L. Psillas, and B. Yanites, 2006: Evolution of the Bonneville shoreline scarp in west-central Utah: Comparison of scarp-analysis methods and implications for the diffusion model of hillslope evolution. Geomorphology, 74, 257-270, doi: 10.1016/j.ge omorph.2005.08.008. [Link] 
Philip, H. and M. Meghraoui, 1983: Structural analysis and interpretation of the surface deformations of the El Asnam earthquake of October 10, 1980. Tectonics, 2, 1749, doi: 10.1029/TC002i001p00017. [Link]

Philip, H., E. Rogozhin, A. Cisternas, J. C. Bousquet, B. Borisov, and A. Karakhanian, 1992: The Armenian earthquake of 1988 December 7: Faulting and folding, neotectonics and palaeoseismicity. Geophys. J. Int., 110, 141-158, doi: 10.1111/j.1365-246X.1992.tb0 0718.x. [Link]

Song, S. R., T. M. Chen, S. Tsao, H. F. Chen, and H. C. Liu, 2007: Lahars in and around the Taipei basin: Implications for the activity of the Shanchiao fault. $J$. Asian Earth Sci., 31, 277-286, doi: 10.1016/j.jseaes.20 06.07.017. [Link]

Sun, M. K., 1995: Reflection seismic study in Nankan fault, Taoyuan area. Master Thesis, National Central University, Jhongli, Taiwan, ROC. (in Chinese)

Suppe, J., 1981: Mechanics of mountain building in Taiwan. Memo. Geol. Soc. China, 4, 67-89.

Teng, K. H., T. H. Tung, C. J. Chen, and P. S. Yeh, 2003: A study on the relationship between Hokou active fault and its tectonic terraces, Taoyuan tableland. J. Taipei Munic. Teach. Coll., 34, 135-156. (in Chinese)

Teng, L. S., 1996: Extensional collapse of the northern Taiwan mountain belt. Geology, 24, 949-952, doi: 10.11 30/0091-7613(1996)024<0949:ECOTNT>2.3.CO;2. [Link]

Teng, L. S. and S. R. Song, 2007: The stratigraphic correlation of Linkou Tableland and Kuiyinshang Volcano, Taiwan Geosciences Assembly 2007, Abstract.

Teng, L. S., C. T. Lee, C. H. Peng, W. F. Chen, and C. J. Chu, 2001: Origin and geological evolution of the Taipei basin, Northern Taiwan. West. Pac. Earth Sci., 1, 115-142.

The Research Group for Active Faults of Japan, 1980: Active faults in and around Japan: The distribution and the degree of activity. J. Nat. Disas. Sci., 2, 61-99.

The Research Group for Active Faults of Japan, 1992: Maps of Active Faults, University of Tokyo Press, Tokyo, Japan.

Tien, J. L., W. H. Wang, C. J. Chu, and C. H. Chen, 1995: The depositional time of the Linkou Formation as revealed by the zircon FTD Ages for Quaternary volcanic rocks in northern Taiwan. J. Geol. Soc. China, 37, 189-241.

Tsai, C. H., 2007: A study of Nankan fault using the electrical resistivity image profile method. Master Thesis, National Central University, Jhongli, Taiwan, ROC. (in Chinese)

Tsai, C. S., 1986: Gravity and microearthquake studies in the Nankan, Tauyuan area. Master Thesis, National Taiwan University, Taipei, Taiwan, ROC. (in Chinese)

Tucker, G. E. and R. L. Slingerland, 1994: Erosional dynamics, flexural isostasy, and long-lived escarpments: A numerical modeling study. J. Geophys. Res. 99, 12229-12243, doi: 10.1029/94JB00320. [Link]

Wang, C. Y. and C. T. Sun, 1999: Interpretation of seismic stratigraphy in the Taipei Basin. Central Geological Survey Special Publication, 11, 273-292. (in Chinese)

Wang, K. L., S. L. Chung, C. H. Chen, R. Shinjo, T. F. Yang, and C. H. Chen, 1999: Post-collisional magmatism around northern Taiwan and its relation with opening of the Okinawa Trough. Tectonophysics, 308, 363-376, doi: 10.1016/S0040-1951(99)00111-0. [Link]

Wang, Y., 2003: Morphotectonics in Taoyuan-Hsinchu Area, Northwestern Taiwan. Master Thesis, National Taiwan University, Taipei, Taiwan, ROC. (in Chinese)

Wang Lee, C. M., 1969: Petrology and origin of the Linkou Gravel in Taipei, Taiwan, China. Proc. Geol. Soc. China, 12, 49-64.

Wei, K., Y. G. Chen, and T. K., Lu, 1998: Sedimentary history of the Taipei Basin with constraints from thermoluminescence dates. J. Geol. Soc. China, 41, 109125.

Wesson, R. L., E. J. Helley, K. R. Lajoie, and C. M. Wentworth, 1975: Faults and future earthquakes. In: Borchardt, R. D. (Ed.), Studies for Seismic Zonation of the San Francisco Bat Region, US Geological Survey Professional Paper 941A, 5-30.

Yang, G. S., 1986: A Geomorphological study of active faults in Taiwan. Ph.D. Dissertation, Chinese Culture University, Taipei, Taiwan, ROC. (in Chinese)

Yeh, Y. H., S. J. Yuen, and Y. B. Tsai, 1985: Application of gravity surveys and microearthquake for investigation of active faults in Taoyuan and Hsihchu area. Technological report of Hazard prevention, National Science Council, Taipei, Taiwan, ROC, No. 74-20. (in Chinese)

Yu, S. B., H. Y. Chen, L. C. Kuo, C. S. Hou, and J. F. Lee, 1999: A study on the fault activities of the Taipei Basin. In: Chen, C. H. (Ed.), Special Issue for the Subsurface Geology and Engineering Environment of the Taipei Basin, Central Geological Survey, MOEA, Taipei, Taiwan, ROC, 227-251.

Zhang, K, 2008: Identification of gaps in mangrove forests with airborne LIDAR. Remote Sens. Environ., 112, 2309-2325, doi: 10.1016/j.rse.2007.10.003. [Link] 